\title{
PAIN RELIEF AND PALLIATIVE CARE
}

\author{
Graham Arthurs* \\ Consultant Anaesthetist, Maelor Hospital, Wrexham, UK \\ and President of the Welsh Pain Society \\ *Corresponding author: grahamarthurs@btinternet.com
}

Key words: Pain relief, Palliative care, Symptom control, Opioids

The International Association for the Study of Pain has declared 2009 a Year against Cancer Pain $^{(1)}$. The aim is that no one should suffer in pain due to cancer. Specialist palliative care physicians have a role in leading the way, educating and dealing with the difficult cases. But every clinician has a part to play in palliative care. Anaesthetists will see the patient who is terminally ill during preoperative assessment and in intensive care when deciding when to admit a patient and in making end of life decisions. Anaesthetists are most involved with the use of opioids and other pain relieving drugs postoperatively and in chronic pain. This puts them in a key position to help with pain relief in the dying patient.

\section{Role of the Anaesthetist}

The anaesthetist is involved because the surgeon will offer the patient an operation while the physician offers another procedure or drug. They see a lack of a cure as a failure. In reality it needs a team of doctors and nurses working together to look after the patient when there is no longer a cure. There are groups of patients that we see regularly. The inoperable cancer and others that are open and shut operations; the advanced vascular disease leading to ischaemic bowel, ischaemic legs or myocardial infarction; extensive burns; wasting neuro-muscle diseases and the diabetic with advanced sepsis.

Consider what we should do for these cases:

a) An elderly man with cancer of the colon and peritonitis. He has intestinal obstruction and is in respiratory and renal failure with a low blood pressure and no urine output. The surgeons want to do a laparotomy

b) A 54 year old lady who has had many admissions for alcohol related events including bleeding from oesphageal varices. She is deeply jaundice and has been unrousable for 4 days. The physician wants her to have General Anaesthesia for an oesaphagogastroduodenostomy and insertion of a jejunal feeding tube.

The problem in both cases is

a) failure to recognise that the patient is dying,

b) failure to communicate accurately with colleagues and relatives

c) failure to have another plan

d) failure to follow the patient through.

Anaesthetists are in a key place to promote good symptom control, good communication with all concerned, realistic aims, avoid side effects and inappropriate therapies and include the family in the process of care.

The crucial stage is the point at which the decision is made that an operation, a procedure such as intensive theatre unit and ventilation, treatment such as chemotherapy or radiotherapy is not appropriate. Also recognition that all treatment has its adverse out comes.

\section{Palliative care}

The phrase palliative care was introduced to mean, an approach that improves the quality of life of patients and their families facing the 
problems associated with life-threatening illness ${ }^{(2)}$. This involves another philosophy of care without denial, avoidance and fear of painful truths. Attention to the control of symptoms such as pain and anxiety and good communication with relatives about the overall care.

There may be an overlap of palliative care with disease modifying therapy until the latter is no longer realistic (table 1).

\section{Table 1}

\section{Progress from curative to palliative care.}

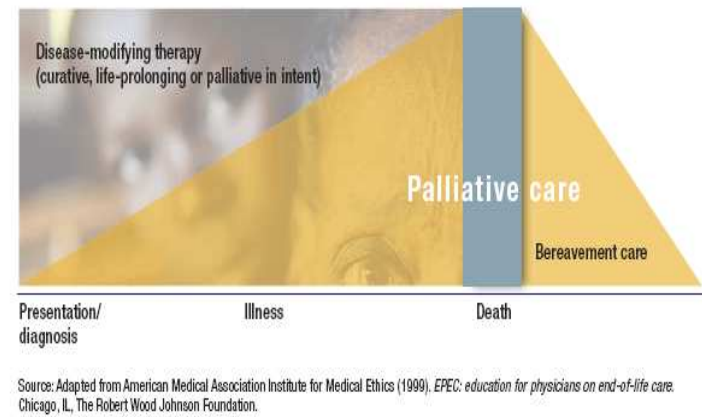

\section{Symptom control}

Pain relief

Pain can be divided into nociceptive (tissue damage), neurogenic (nerve damage), sympathetic (colic, ischaemia), emotional (fear and depression) and factitious or dysfunctional (pain with no evidence of disease on examination or investigation).

More than $70 \%$ of cancer patients have moderate to severe pain ${ }^{(3-5)}$. Pain relief has many facets but for many patients a combination of a nonsteroidal anti-inflammatory drug with an opioid is very effective ${ }^{(6)}$ for nociceptive pain. Unfortunately opioids are not easily available in many parts of the world and treatment is a problem.

In 2006 Europe and North America consumed $89 \%$ of global morphine, $98 \%$ of global oxycodone and $96 \%$ of global fentanyl.

The limited availability of codeine and morphine through a pharmacist is shown in table $2^{(7)}$.
Availability of codeine and morphine in developing countries

Percentage of pharmacists at which drug was available

$\begin{array}{lcc}\text { Codeine tablets } & \begin{array}{c}\text { Morphine } \\ \text { sulphate }\end{array} \\ \text { Bangladesh } & 0 & 0 \\ \text { Brazil } & 0 & 0.1 \\ \text { Malawi } & 5.6 & 30.0 \\ \text { Nepal } & 13.8 & 0 \\ \text { Pakistan } & \text { not available } & 0 \\ \text { Sri Lanka } & 0 & 12.4\end{array}$

Bulletin of the World Health Organisation 2007; 85:279284

Table 2

The barriers to effective pain management include:

1. Problems related to health care professionals' lack of knowledge and misconceptions about the use of opioids and a failure to apply basic pharmacological principles in using morphine.

2. Problems related to patients not reporting pain and side effects and fears about taking opioids

3. Problems related to the health care system. Cancer pain is given a low priority. Drugs that need to be given over time may be expensive or difficult to obtain on a regular basis.

There are legitimate concerns about opioids. These include the people who want to use the drug for the pleasant hallucinations of well being that they experience. The characteristic of this drug induced sense of well being is sudden onset as by intravenous or inhaled administration, short duration of action one to two hours an increasing dose to achieve the effect, and unpleasant withdrawal symptoms such as sweating and abdominal cramps. These concerns can be solved by doctors accepting responsibility for only prescribing the drug in reasonable doses, when it gives three to five hours of pain relief in patients with a diagnosis of cancer of pain. The opioid is 
then dispensed only through licensed pharmacists with good record keeping.

Side effects like constipation need to be treated with daily laxatives and any unpleasant feelings may need to be relieved with a benzodiazepine (diazepam 2mg).

The WHO ladder for pain relief starts with a nonsteroidal anti-inflammatory drug (NSAID), then a weak opioid and then a strong opioid or a nerve block. The NSAID relieves pain by blocking cyclo-oxygenase which produces prostaglandins. Prostaglandin sensitises the nociceptor to fire at a lower threshold when stimulated by other mediators such as those released in inflammation. Prostaglandin is produced in large amounts by osteolytic secondary bone tumours and the prostate, so a larger dose of NSAID can be very effective in relieving this severe pain. The main side effects with NSAIDs are their tendency to aggravate peptic ulcer disease, asthma and renal failure.

Most opioids have a similar structure and produce pain relief by occupying the mu receptor (table 3 ). They are converted to morphine in the body by the cytochrome P 450 system. Weaker opioids are less potent forms of morphine, not different analgesics. So $30 \mathrm{mg}$ of codeine will be equivalent to about 0.5 to $1.0 \mathrm{mg}$ morphine in the body but it causes much more constipation.

Fig. 1

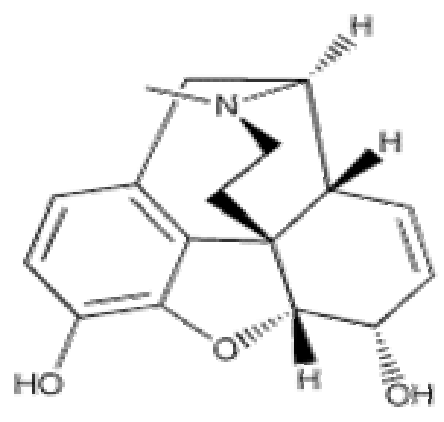

Morphine
Fig. 2

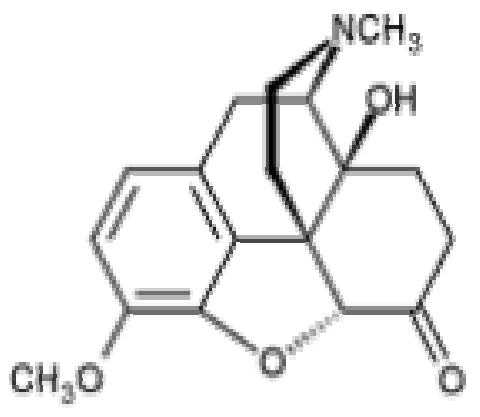

\section{Oxycodone}

Fig. 3

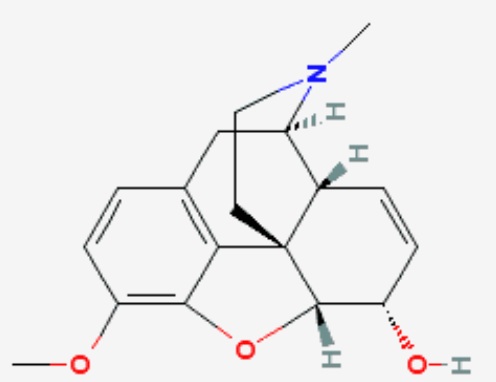

\section{Codeine}

Fig. 4

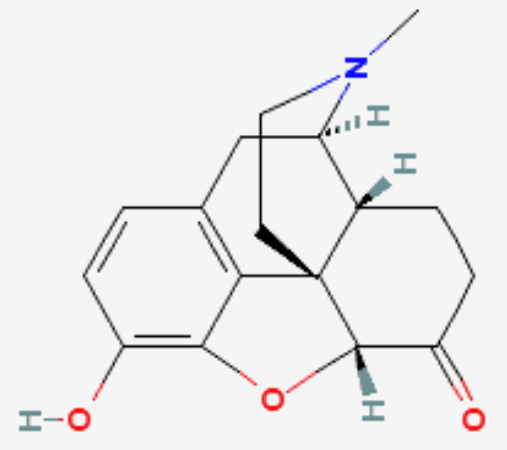

\section{Hydromorphone}

Shows the phenathrene ring structure of morphine and the variation in the structure in oxycodone, codeine and hydromorphone 
One of the main advances in pharmacology in the past 20 years has been the development of better drug delivery systems. The cheapest opioid is morphine powder that can be given orally in solution or by subcutaneous injection using a syringe driver, sublingual, suppositories, patches and implanted delivery systems which are now available as well as the use of opioids in regional nerve blocks.

Dose equivalents can be a problem but is always best to start with a smaller dose and give more by increments until an effective dose is reached.

\begin{tabular}{|l|l|l|l|l|}
\hline \multirow{2}{*}{ Drug } & \multicolumn{4}{|c|}{ Dose (mg) equivalent to morphine } \\
\cline { 2 - 5 } & Oral & $\begin{array}{l}\text { IM/ } \\
\text { IV }\end{array}$ & $\begin{array}{l}\text { Half-life } \\
\text { (hours) }\end{array}$ & $\begin{array}{l}\text { Duration } \\
\text { of action } \\
\text { (hours) }\end{array}$ \\
\hline Morphine liquid & $\begin{array}{l}20- \\
30\end{array}$ & 10 & $2-3$ & $3-4$ \\
\hline $\begin{array}{l}\text { Morphine } \\
\text { controlled release }\end{array}$ & $\begin{array}{l}20- \\
30\end{array}$ & 10 & $2-3$ & $8-12$ \\
\hline Hydromorphone & 7.5 & 1.5 & $2-3$ & $3-4$ \\
\hline Oxycodone & 20 & & $2-3$ & $3-4$ \\
\hline $\begin{array}{l}\text { Oxycodone slow } \\
\text { release }\end{array}$ & 20 & & $2-3$ & $8-12$ \\
\hline Fentanyl patch 25 & & & $16-24$ & 72 \\
\hline
\end{tabular}

Table 3

\section{Opioid dose equivalents}

Codeine is converted to morphine by cytochrome P450 2D6. It causes bowel smooth muscle contraction and is the most constipating of all the opioids by putting the bowel smooth muscle into spasm. It is a good cough suppressant controller (antitussive).

Tramadol is also a weak synthetic opioid ${ }^{(8)}$.

Methadone is a synthetic opioid not recommended for pain relief as it has an unpredictable half life and duration of action. It is no longer thought to have a significant ( $\mathrm{N}$-methyl M D-aspartate (NMDA) effect.

Transdermal fentanyl and other patches are useful for patients who have difficulty in swallowing ${ }^{(9)}$.

\section{Guidelines for prescribing opioids}

Use the oral route whenever possible.

Start with 10 to $15 \mathrm{mg}$ morphine orally per 24 hours ( 2 to 3 mg every 4 hours $)^{(10,11)}$.
Always give the next dose before the last dose wears off.

Always prescribe a laxative.

Increase the dose by $50 \%$ if the last dose was not effective.

Prescribe a rescue dose of $50 \%$ the regular dose.

for break through pain.

Treat any side effects: constipation, sedation, dreams, myoclonus, nausea but exclude constipation, peptic ulcer and other causes first, and pruritis $^{(12)}$.

Side effects of opioids and other symptoms

It is important to try to identify the cause and then most symptoms are easy to manage.

Constipation - a common cause of nausea. Stimulate the bowel with senna; increase the stool bulk with magnesium salts or lactulose and soften the stool with ducosate or an enema.

Sedation.

The patient may initially fall asleep when given morphine as pain and disease cause exhaustion. If the sleepiness continues for days then try reducing the dose, use another opioid, and consider other causes like infection. Methylphenidate $5 \mathrm{mg}$ may help. Distinguish between sleepiness and withdraw due to depression.

Nausea.

It is important to exclude a cause such as constipation, peptic ulcer, hypercalcaemia and worry and fear. Opioid induced vomiting is rare and will respond to cyclizine or hyoscine. Dreams and fear respond to midazolam or other sedatives. Haloperidol is effective in controlling nonspecific nausea and vomiting.

\section{Vomiting}

Exclude bowel obstruction including constipation, peptic ulcer or gastritis or a high calcium. Try haloperidol or pass a small bore nasogastric tube to empty the stomach in terminal obstruction.

Breathlessness is made easier when sitting upright, with a fan and avoid dry air. Opioids stop coughing, hyperventilation and the feeling of "I 
cannot get my breath"; the benzodiazepines reduced the associated sense of panic. Steroids may help. Draining a pleural effusion or abdominal ascites may give relief.

Neurogenic pain.

Neurogenic pain is caused by pressure, irritation or erosion of a nerve. The pain is in the nerve distribution and there is associated allodynia, hypo- or hyper- algesia. Radiating pain can also be myotomal.

Specific tricyclic drugs like amitriptiline 10mg and dusolepin $25 \mathrm{mg}$ at night with an anticonvulsant such as pre-gabaline $75 \mathrm{mg}$ bd, carbamazepine or sodium valproate may be effective. Consider radiotherapy single dose or steroids to reduce the swelling.

Corticosteroids have many benefits at the end of life and their side effects are less relevant. They reduce oedema around nerve irritation but retain fluid and so mask weight loss; they increase appetite and give a sense of well being.

Difficult pains

In recent years attention has focused on variations in gene function to explain individual variations in response to opioids ${ }^{(13)}$. The cytochrome P450 enzymes and lack of CYP2DP in particular is the key to the final conversion of codeine, hydromorphone and oxycodone into morphine. This is the reason for interactions with drugs like the SSRI antidepressants. Variants in P450 may account for why there is individual variation in effectiveness of different drugs. The membrane transporter MDR-1 pumps morphine out of the cell and may account for why the duration of action is altered in some people. The mu receptor can change and patients with a mutation A118G or $G$ allele variant have a poor response to morphine.

\section{Communication}

We communicate with words and in gestures. The three monkeys illustrate the old truisms of wanting to see no evil, hear no evil and speak no evil communicated in actions not words (Fig. 5).

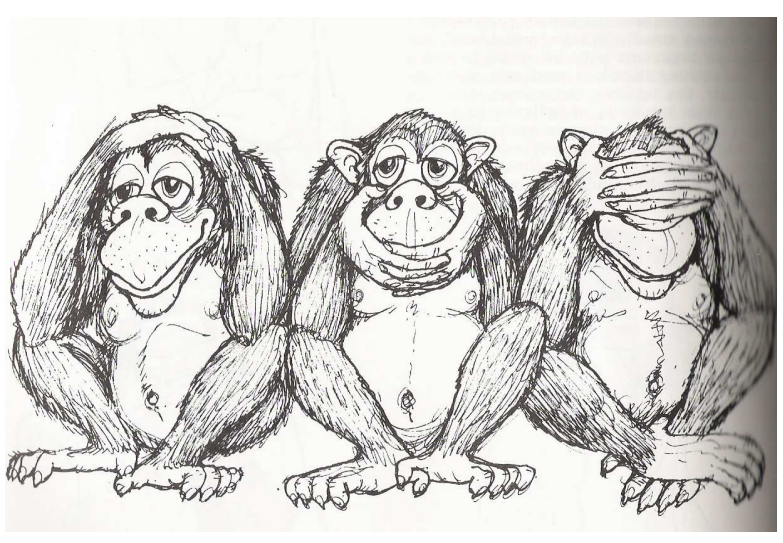

Fig. 5

Three wise monkeys. Hear no evil, speak no evil and see no evil.

Patients are very sensitive to lack of eye contact, a serious look and evasive answers to questions when it comes to knowing something is wrong. The giving of bad news is never easy as it is as painful to the giver as it is to the receiver. But it is essential as a starting point for the palliative care.

What is needed is not a new drug or a better understanding of the problems, rather a consistent and rational application of what we already know.

\section{References}

1. www.iasp-pain.org Section Global Year Against Pain.

2. www.who.int/cancer/palliative/definition

3. Meier DE. Overview of Cancer Pain and Palliative Care Journal of Pain and Symptom Management 2003; 24:265-269.

4. Vainio A, Auvinen A. Prevalence of symptoms among patients with advanced cancer: an international collaborative study. Journal of Pain and symptom management 1996; 12:3-10.

5. Ventafridda V. Cancer Pain management. Pain Reviews 1996; 3:153-179.

6. Veilhaber A. Portenoy RK. Advances in cancer pain management. Haematology/ oncology Clinics of North America 2002;16.

7. Availability (\% of pharmacists selling the drug) in low income countries. WHO Bulletin 2007;85:279-284.

8. Leppert $\mathrm{W}$, Luczak J. The role of tramadol in cancer pain treatment - a review Support Care Cancer 2005; 13(1):15-17 Epub 2004 Nov 18. 
9. Skear TL Transdermal opioids for cancer pain. Health and Quality of life outcomes 2006; 4:24.

10. Mercadante S, Villari P, Ferrere P, Casuccio A. Opioid-induced or pain relief-reduced symptoms in advanced cancer patients? European Journal of Pain 2006a; 10:1253-9.

11. Mercadante S, Porzio G, Ferrere P, Fulfaro F, et al. Low morphine dose in opioid naive cancer patients with pain. Journal of Symptom Management 2006b; 31:242-7.

12. McNicol E, Management of Opioid side effects in cancer-related and chronic noncancer pain: A systematic review. The Journal of Pain 1003; 4(5):231-256.

13. Smith HS Variations in opioid responsiveness. Pain physician 2008;11:237248.

$* * * * * * * * * * * * * * * * * * * * * * * * * * * * * * * * * * * * * * * * * * * * * * * * * * * * * * * * * * * * * * * * * * * * * * *$

THE COLLEGE OF ANAESTHESIOLOGISTS OF SRI LANKA

LECTURE DEMONSTRATION \& CERTIFICATION

ON

\section{Cardio Pulmonary Resuscitation}

$\begin{array}{cc}\text { Venue - } & \begin{array}{c}\text { Trauma Lecture Hall } \\ \text { National Hospital, Sri Lanka } \\ \text { Date }\end{array} \\ \text { Time } & \text { on Tuesdays } \\ & 9.00 \mathrm{am} \\ & \text { Conducted by } \\ \text { Dr Shirani Hapuarachchi } \\ \text { Consultant Anaesthetist, NSU } \\ \text { Contact } \\ \text { Ms Chamila Gamage, } \\ \text { Office Secretary, 2672327/2691111-Ext } 2571\end{array}$

$* * * * * * * * * * * * * * * * * * * * * * * * * * * * * * * * * * * * * * * * * * * * * * * * * * * * * * * * * * * * * * * * * * * * *$ 